\title{
O CUIDADO NO PRÉ-NATAL: UM VALOR EM QUESTÃO*
}

\author{
Luana Asturiano da Silva ${ }^{1}$, Valdecyr Herdy Alves $^{2}$, Diego Pereira Rodrigues ${ }^{3}$, Márcia Vieira dos Santos ${ }^{4}$, \\ Juliana Vidal Vieira Guerra ${ }^{5}$, Giovanna Rosário Soanno Marchiori ${ }^{6}$
}

\begin{abstract}
RESUMO: O estudo objetivou compreender os valores instituídos nos discursos dos profissionais da saúde sobre a assistência pré-natal. Estudo fenomenológico, realizado com a técnica da entrevista semiestruturada, no período de janeiro a abril de 2015, com 14 profissionais de saúde (médicos e enfermeiros) de quatro Unidades da Atenção Básica do município de Niterói, Rio de Janeiro, Brasil. Os depoimentos foram submetidos à análise compreensiva e interpretados com base na Teoria dos Valores de Max Scheler, permitindo emergir duas categorias: $\mathrm{O}$ valor vínculo como processo de qualidade para o acompanhamento pré-natal: o valor afetivo; $\mathrm{O}$ olhar para a prevenção como valor vital na consulta do pré-natal. Desse modo, os profissionais relataram uma concepção vital de seus valores com base no pensamento Scheleriano, e somados para que a rede de atenção ao pré-natal tenha uma adequação com foco na mulher, em prol de um avanço qualificado da assistência pré-natal. DESCRITORES: Obstetrícia; Cuidado pré-natal; Enfermagem; Valores sociais.
\end{abstract}

\section{PRENATAL CARE: A VALUE IN QUESTION}

ABSTRACT: The study aimed to comprehend the values established in the discourses of health professionals regarding prenatal care. This phenomenological study was conducted using the semi-structured interview technique, from January to April 2015 , with 14 health professionals (physicians and nurses) from four Primary Care Units of the city of Niterói, Rio de Janeiro, Brazil. The statements were submitted to comprehensive analysis and interpreted based on Max Scheler's Theory of Values, allowing two categories to emerge: The bond as the process of quality for prenatal monitoring: the affective value; The perspective of prevention as the vital value in the prenatal consultation. Thus, the professionals reported a vital concept of their values based on Schelerian thinking and added that the prenatal care network has a woman-centered approach towards a qualified advance in prenatal care.

DESCRIPTORS: Obstetrics; Prenatal care; Nursing; Social values.

\section{EL CUIDADO EN PRENATAL: UN VALOR EN CUESTIÓN}

RESUMEN: Estudio cuya finalidad fue comprender los valores implícitos en los discursos de los profesionales de salud acerca de la asistencia prenatal. Estudio fenomenológico, realizado con la técnica de entrevista semi estructurada, en periodo de enero a abril de 2015, con 14 profesionales de salud (médicos y enfermeros) de cuatro Unidades de Atención Básica del municipio de Niterói, Rio de Janeiro, Brasil. Los testimonios fueron sometidos al análisis comprensivo e interpretados con base en la Teoría de los Valores de Max Scheler, resultando en dos categorías: El valor del vínculo como proceso de cualidad para el acompañamiento prenatal: el valor afectivo; La prevención como valor vital en la consulta del prenatal. De ese modo, los profesionales relataron una concepción vital de sus valores con base en el pensamiento scheleriano, añadidos para que la red de atención al prenatal tenga una adecuación con énfasis en la mujer, a favor de un desarrollo cualificado de la asistencia prenatal.

DESCRIPTORES: Obstetricia; Cuidado prenatal; Enfermería; Valores sociales.

\footnotetext{
*Artigo extraído da dissertação intitulada: "Assistência pré-natal na rede municipal de Niterói: A ótica valorativa dos profissionais de saúde". Universidade Federal Fluminense, 2015.

${ }^{1}$ Enfermeira. Mestre em Enfermagem. Universidade Federal Fluminense. Niterói, RJ, Brasil.

${ }^{2}$ Enfermeiro. Doutor em Enfermagem. Docente da Universidade Federal Fluminense. Niterói, RJ, Brasil.

${ }^{3}$ Enfermeiro. Mestre em Enfermagem. Docente do Centro Universitário Anhanguera de Niterói. Niterói, RJ, Brasil.

${ }^{4}$ Enfermeira. Mestre em Saúde Materno Infantil. Enfermeira da Secretaria de Estado de Administração Penitenciária. Rio de Janeiro, Brasil. Niterói, RJ, Brasil.

${ }^{5}$ Nutricionista. Mestranda em Saúde Materno Infantil. Nutricionista da Prefeitura Municipal de São João da Barra. Niterói, RJ, Brasil.

${ }^{6}$ Enfermeira. Mestre em Saúde Materno Infantil. Docente da Faculdade Novo Milênio. Vitória, ES, Brasil.
}

Autor Correspondente:

Diego Pereira Rodrigues

Recebido: 06/12/2016

Centro Universitário Anhanguera de Niterói

R, Desembargador Leopoldo Muylaert, 307 - 24350-450 - Niterói, RJ, Brasil

E-mail: diego.pereira.rodrigues@gmail.com 


\section{INTRODUÇÃO}

O pré-natal mostra-se como forte aliado na luta contra a morbimortalidade materna, perinatal e neonatal e, na perspectiva do cuidado e de suas potencialidades acolhedoras, o conhecimento vem provocando importantes reflexões e questionamentos a respeito da atuação dos profissionais da área da Saúde da Mulher. Nesse sentido, a maior proximidade entre profissionais e gestantes é de extrema relevância, uma vez que favorece o vínculo e proporciona a humanização da assistência ${ }^{(1)}$.

O cuidado humanizado torna possível a aproximação necessária para que a relação entre cuidador e pessoa cuidada se estabeleça de forma a atender à complexidade do período gravídico, isto porque o 'sentir' e o 'viver' o mesmo que o outro, ocorre por meio da simpatia, sendo o amor uma consequência de um comportamento simpatizante ${ }^{(2)}$.

As políticas públicas corroboram a perspectiva de que humanização e qualidade da atenção em saúde estão intimamente ligadas, sendo essenciais para que as ações de saúde tenham como foco a resolução dos problemas identificados, assim como a satisfação das usuárias; e ainda, elucidam que a humanização e a qualidade são questões de direitos humanos. Por isso, humanizar e qualificar a atenção em saúde é aprender a compartilhar saberes e reconhecer direitos ${ }^{(1)}$.

A lógica "tecnoburocrática" centrada no modelo biomédico vigente, engessa o cuidado pautado no intervencionismo predominante em técnicas que isolam o cliente, tratando-o como receptor de protocolos e procedimentos (invasivos ou não) ${ }^{(3)}$. Além disso, este modelo tecnocrático prioriza o corpo da mulher como algo patológico, que necessita de intervenção e que influencia a vida da mulher no processo de parir ${ }^{(4)}$.

Há um grande desafio no sentido de promover a humanização da assistência, e uma das dificuldades está em entender a importância da fala do outro, ou seja, identificando se a fala do outro é desqualificada, não reconhecida, ou se seus argumentos são sequer colocados, destarte inviabilizando qualquer hipótese de entendimento ou ação comunicativa emancipadora ${ }^{(1,3-5)}$.

Assim, como se pode perceber, a mudança do modelo de atenção é um processo complexo que depende da incorporação de modificações no processo de trabalho em saúde quanto aos seus propósitos, objetos, meio e, principalmente, às relações entre profissionais e população usuária dos serviços. Por isso, esta mudança só será efetivada quando o papel central do sujeito no cuidado for reconhecido ${ }^{(6)}$.

Com este estudo, pretendeu-se obter a ampliação do conhecimento na área de pré-natal, uma vez que seus resultados permitiram identificar as práticas dos profissionais de saúde no processo do cuidado, assim viabilizando pensar em estratégias de fortalecimento de subsídios para o enfrentamento de uma atenção qualificada à gestante.

Nessa linha de raciocínio, o estudo teve como questão norteadora: "Quais são os valores intuídos nos discursos dos profissionais da saúde que realizam o pré-natal?", e como objetivo, compreender os valores instituídos nos discursos dos profissionais da saúde sobre a assistência pré-natal.

\section{- MÉTODO}

Estudo descritivo, exploratório, de cunho fenomenológico com abordagem qualitativa no campo da Teoria dos Valores de Max Scheler. O teórico tem como pressuposto que os valores são oriundos da intuição emocional, sendo contrário ao pensamento Kantiano, de que o valor vem da perspectiva da razão, e a partir dessa intuição, e por conta da dimensão carencial do sujeito, o mesmo agrega os valores tendo como intuito o preenchimento de suas carências a fim de se tornar um ser em plenitude( ${ }^{(7)}$.

Os participantes do estudo foram 14 profissionais da saúde, sendo seis enfermeiros e oito médicos. Todos realizavam o acompanhamento pré-natal na atenção básica na Fundação Municipal de Saúde de Niterói, município integrante da Região Metropolitana II do Estado do Rio de Janeiro, Brasil. Os cenários escolhidos para o estudo foram: Policlínica Regional de Itaipu; Policlínica Regional Dr. Sério Arouca; Policlínica Regional do Largo da Batalha; e Policlínica Regional Dr. Carlos Antônio da Silva. 
Essas unidades são de nível secundário na assistência e não pertencem à rede da Estratégia Saúde da Família (ESF) do município.

Os critérios de elegibilidade no estudo foram: ser profissional da saúde que realiza consultas e/ ou integra grupos de pré-natal; estar atuando junto ao pré-natal há pelo menos seis meses. Foram excluídos os profissionais que estivessem de licença médica, licença maternidade ou em gozo de férias no período de coleta de dados, e também aqueles em processo de treinamento, por terem sido admitidos há menos de seis meses no serviço. Assim, foram entrevistados todos os que atenderam aos critérios descritos.

Para ilustrar os participantes, segue-se a relação das Unidades com o respectivo número de profissionais. Optou-se por discriminar as Unidades como I, II, III e IV para preservar os nomes das instituições.

Quadro 1 - Número de profissionais por unidade pesquisada. Niterói, RJ, Brasil, 2015

\begin{tabular}{|l|c|c|c|c|}
\hline Profissional & Unidade I & Unidade II & Unidade III & Unidade IV \\
\hline Enfermeiro & 3 & 1 & 1 & 1 \\
\hline Médico & 2 & 3 & 3 & 3 \\
\hline
\end{tabular}

Com base nos dados acima, o número de profissionais nas Unidades totaliza dezessete, contudo um estava de férias e dois não aceitaram participar do estudo. Sendo assim, esses três profissionais foram excluídos, perfazendo quatorze o total dos participantes.

O aceite dos profissionais de saúde em participar da pesquisa deu-se a partir do esclarecimento do tema a ser abordado e da solicitação da assinatura do Termo de Consentimento Livre e Esclarecido (TCLE), documento que condiciona a participação voluntária no estudo, sendo assegurado a cada um o anonimato e o sigilo das informações, confirmados com a utilização de um código alfanumérico (E1...E14) de acordo com a realização das entrevistas, assim viabilizando a aplicação do instrumento de coleta de dados.

Em conformidade com a Resolução $n^{\circ}$ 466, de 12 de dezembro de 2012, do Conselho Nacional de Saúde(8), o estudo foi aprovado em 02 de dezembro de 2014 pelo Comitê de Ética em Pesquisa da Faculdade de Medicina do Hospital Universitário Antônio Pedro da Universidade Federal Fluminense, sob Protocolo ${ }^{\circ}$ 895.033/2014.

A técnica utilizada para a coleta de dados foi a entrevista semiestruturada individual, a partir de roteiro elaborado com perguntas fechadas e abertas, possibilitando aos participantes discorrerem sobre o tema em questão, sem se prender à indagação formulada. As entrevistas foram realizadas no local de serviço dos profissionais de saúde, com prévio agendamento, e ocorreram no período de janeiro a abril de 2015.

As entrevistas tinham questões relacionadas à formação profissional, prática nas consultas do pré-natal, descrição da importância da consulta na saúde da mulher, etapas realizadas na consulta e opiniões sobre as dificuldades na assistência pré-natal no município, a partir de sua realidade.

Os depoimentos dos profissionais de saúde foram gravados em aparelho digital com a prévia autorização de cada entrevistado, e transcritos na íntegra pela pesquisadora com a finalidade de assegurar a fidedignidade das falas. As transcrições originaram os sentidos valorativos(9) do estudo, os quais foram organizados de acordo com a técnica de análise compreensiva(9) e, finalmente, interpretados com base na Teoria dos Valores de Max Scheler(7).

Os sentidos valorativos fundamentaram a construção das seguintes categorias: $1^{\text {a) }}$ O vínculo como processo de qualidade para o acompanhamento pré-natal: o valor afetivo; $2^{\mathrm{a}}$ ) O olhar para a prevenção como valor vital na consulta do pré-natal. 


\section{RESULTADOS}

Dentre os 14 profissionais de saúde, obteve-se um total de seis enfermeiros e oito médicos, com faixa etária predominante entre 41 e 54 anos de idade, englobando oito participantes, do restante, três tinham entre 32 e 35 anos, e três com mais de 61 anos de idade. Quanto ao gênero havia 12 mulheres e dois homens.

No que diz respeito à especialização, 11 profissionais tinham realizado, sendo que sete na Área de Saúde da Mulher. Com relação ao tempo de conclusão do curso, quatro profissionais concluíram entre um e três anos; um entre quatro e 10 anos; e seis há mais de 10 anos. Quando questionados a respeito de realização de cursos de atualização, 10 participantes responderam afirmativamente, sendo que a maioria (11) realizou o último curso entre um a três anos.

\section{Vínculo como processo de qualidade para o acompanhamento pré-natal: o valor afetivo}

Nesta primeira categoria, o valor vínculo mostrou-se arraigado no sentir emocional dos participantes, um valor para a manutenção da vida, vital para um acompanhamento pré-natal de qualidade. Sendo assim, o sentido valorativo para um cuidado integral no pré-natal; o valor da confiança no processo de cuidado; o acolhimento no pré-natal; conhecer a gestante para cuidar, foram contemplados nos depoimentos a seguir:

O acolhimento à gestante é fundamental, [...] quanto melhor eu acolho, mais garantia eu tenho que ela vá fazer as consultas preconizadas.(E2)

A gente cria vínculo, elas me conhecem pelo primeiro contato [...] umas ficam íntimas. Muitas coisas assim são descobertas.(E4)

É muito satisfatório porque tem muita gestante que vem para as consultas e aderem mesmo, que não faltam, trazem o marido, trazem os outros filhos, [...], quando é muito "largada", as pessoas ficam meio perdidas. (E7)

Nesse sentido, percebe-se que os profissionais de saúde recorreram à ideia do vínculo, enfatizando a necessidade e a importância de estabelecer uma relação empática com as mulheres sob seus cuidados, tal como relatado:

A partir do momento que você consegue ganhar a confiança dessa paciente para que ela venha todos os meses normalmente, ela vai fazer um bom pré-natal[...]. (E8)

Quando eu tenho algum problema e tenho que me afastar, sempre ficam [as gestantes] pedindo para eu voltar logo, trazem presente para mim, trazem presente para meus filhos.(E12)

Em relação às dificuldades para a criação do vínculo e suas consequências, os participantes afirmaram:

Eu trabalho em maternidade pública, e até hoje eu continuo vendo parto sem assistência, paciente sem pré-natal. Ainda tem isso tudo, porque infelizmente as pacientes fogem das consultas. [...] eu acho que elas não querem nem acreditar que estão grávidas[...] ou então é multípara que acha que sabe tudo [...]. (E3)

A gente tem que ficar ligando, pedindo para elas virem, e elas não vêm. Então é muito difícil mostrar para elas a importância do pré-natal [...] e elas aceitarem é difícil. (E14)

Convencer todas as mulheres a participarem é um desafio, eu vejo uma evasão grande [...]. Por isso que é importante fazer com que elas tenham uma adesão maior, nem todas acham que é importante, por mais que você explique. (E11)

O valor na sua essência vital pode ser vivenciado pelos profissionais de saúde, quando se preocupam com a vida dessas mulheres de uma forma abrangente, conforme seus depoimentos:

Eu colho as queixas, vejo todos os exames, já encaminho, já peço novos exames, faço orientação 
com relação a quando vai chegar o neném, que elas perguntam muito, querem saber, explico a ultrassonografia, inclusive preparação para o aleitamento [...].(E5)

Dificilmente eu encaminho a paciente para o pré-natal de alto risco, e acho que tudo isso devido à atenção e a orientação que a gente dá a paciente, os maridos sempre vem, eu peço para que eles venham junto, para ajudarem a esposa não é? (E6)

E o importante é prepará-la psicologicamente para o parto normal, orientá-la para o parto normal, [...] é mais fisiológico[...]. (E9)

É um desafio que ela seja olhada como um todo mesmo [...] mas procurar estar com atenção maior dentro do possível, e quando atender, conversar mesmo, ver o que está acontecendo, porque às vezes elas não verbalizam, não é? (E10)

\section{O olhar para a prevenção como valor vital na consulta do pré-natal}

Nessa segunda categoria, os valores da prevenção do orgânico (relativos ao organismo) estão arraigados como uma questão de valor vital e para a qualidade do acompanhamento do pré-natal, conforme os depoimentos dos entrevistados:

É a partir do pré-natal que conseguimos detectar alterações na formação do bebê que, mesmo quando a gente não consiga tratar no pré-natal, mas para a paciente ter ciência, doenças infectocontagiosas como sífilis para tratar, para que a criança não tenha sequelas, eu acho importantíssimo o pré-natal. (E1)

Quando a gente consegue fazer o pré-natal certinho [...], teoricamente diminui a chance de qualquer complicação no parto e no pós-parto. Quando a gente não consegue, é criança com sífilis, mãe com AIDS sem fazer profilaxia, aí é tudo de ruim. (E3)

A gente faz a triagem para sífilis e o diagnóstico para o HIV [...] está tendo um bom resultado, encaminhando, evitando a sífilis congênita. (E4)

A mulher assim que perceber um atraso menstrual deve procurar imediatamente uma assistência médica, para fazer os primeiros exames. E esse primeiro trimestre é de uma importância vital para o bebê por causa dessas viroses. (E6)

\section{DISCUSSÃO}

Nos depoimentos dos profissionais de saúde há um valor de unidade, ou seja, uma preocupação com o cuidado integral das gestantes, desprendida de interesses particulares, evidenciando os valores vitais do vínculo e do acolhimento levando em consideração a sua integralidade. A propósito, o acolhimento é importante tópico nas políticas públicas de assistência à mulher que norteiam toda a lógica de atenção integral à sua saúde. Sendo assim, o acolhimento da gestante deve demonstrar comprometimento com a totalidade do cuidado, desde a sua chegada ao serviço de saúde, com escuta qualificada que favoreça a criação de vínculo, assim permitindo a melhor avaliação de vulnerabilidades que ela apresenta, condizentes com o seu contexto social ${ }^{(10)}$.

É visível nos depoimentos o sentimento do agradável quando os profissionais de saúde mencionam o esforço para acolher, e depois o resultado alcançado, que é a criação de vínculo e a consequente manutenção do acompanhamento pré-natal, considerada uma conquista. Esse é um valor vital aos sentidos. Desse modo, a superioridade do agradável está direcionada pelo fato dela propiciar o crescimento dos valores vitais ${ }^{(7)}$.

A palavra "vínculo" remete à ligação, tendo os seguintes significados: tudo o que ata, liga ou aperta, aquilo que liga ou estabelece uma relação(11).

É visível, nos depoimentos dos profissionais de saúde, a importância da criação de vínculo no desenvolvimento da confiança, resultando em um pré-natal de melhor qualidade, em que há via de mão dupla no que diz respeito ao cuidado na relação profissional-usuárias. Na medida em que esta 
ligação é concretizada, as consultas tornam-se mais eficazes e, consequentemente, um "porto seguro" para as gestantes ${ }^{(12)}$.

Porém, para criar vínculo, há que se investir em uma relação de qualidade, humanizada. Este tem sido o constante foco das políticas públicas de atenção à saúde, especificamente no pré-natal: o profissional deve permitir que a gestante expresse suas preocupações e angústias, possibilitando a criação de vínculo com a equipe de saúde ${ }^{(12)}$.

A humanização é peça fundamental nesse processo, tendo em vista que uma pessoa só se liga a outra na medida em que haja empenho na relação, ou seja, investimento em ações que tenham como foco o bem estar da outra. A gestante dificilmente irá expor suas questões de qualquer natureza se estiver se sentindo desconfortável para tanto. Somente assim a relação entre profissional e mulher gestante será efetiva e proveitosa ${ }^{(1)}$.

Contudo, dificuldades para a criação do vínculo foram evidenciadas por alguns participantes, conforme citado na primeira categoria: "as pacientes fogem das consultas" (E6), "é muito difícil mostrar para elas a importância do pré-natal" (E2), "nem todas acham que é importante" (E8). Nestas falas, observase certo distanciamento na relação profissional-gestante. Porém, nota-se o tom de preocupação dos entrevistados a respeito do desenrolar do pré-natal, face à dificuldade de fazer com que as gestantes se mantenham assíduas nas consultas do pré-natal, como mostram os recortes das falas:"a gente tem que ficar ligando, pedindo para elas virem", "eu continuo vendo parto sem assistência, paciente sem pré-natal", "é importante fazer com que elas tenham uma adesão maior" (E13).

Nesse sentido, o fenômeno da simpatia estudado por Max Scheler ${ }^{(7)}$ pode esclarecer esse ponto, já que é por meio da simpatia que o outro é reconhecido, e ainda, perante a simpatia é que 'sentimos com' e 'simpatizamos com', o que permite dirigirmo-nos aos outros e realizar emocionalmente a humanidade ${ }^{(13)}$. Refletir acerca do pensamento de Scheler, no que diz respeito à simpatia, corrobora a ideia de que é através de uma ligação verdadeira que o vínculo é construído entre os envolvidos no processo assistencial $^{(7)}$.

Assim, um atendimento de qualidade torna-se essencial já na primeira consulta, com diálogo claro e postura acolhedora, influenciando positivamente na decisão da gestante de vincular-se ao pré-natal e garantindo a continuidade do acompanhamento ${ }^{(1)}$. A simpatia dos profissionais que acompanham o pré-natal é essencial para a continuidade desse cuidado, pois a partir do momento em que "sentimos com" o outro, as duas partes se conectam e as trocas ocorrem mais facilmente.

Na consulta pré-natal, é importante que o profissional de saúde considere os diversos aspectos da vida da gestante para que o cuidado seja realizado abrangendo a sua individualidade. Ademais, a história de vida e o contexto de gestação relatados pela mulher no momento da consulta devem ser levados em consideração(10,12). Dessa forma, torna-se possível um cuidado que irá transpor a gestação.

$\mathrm{Na}$ hierarquia dos valores Schelerianos, apresenta-se o valor de expansão representando o crescimento em diversos sentidos, sendo, portanto, um valor para a essência vital ${ }^{(7)}$. Essa valoração da expansão proporcionará, por meio das conversas e trocas de conhecimento, perspectiva de entendimento entre profissionais e usuárias do serviço, e assim, a consequente manutenção do vínculo estabelecido entre eles.

Um bom profissional de saúde está sempre atento a qualquer relato por entender que os fatores sociais, afetivos e espirituais repercutirão no desenvolvimento da gestação, em como essa mulher se vê e em como ela se sente diante das transformações relativas ao período gravídico e, posteriormente, ao período puerperal. Por essa razão, não se pode perder essa questão de vista, cabendo tornar o pré-natal um momento de vinculação entre profissionais de saúde e gestantes. E aí sim, teremos um cuidado para além do biológico.

Seguindo a lógica da Teoria de Valores de Max Scheler, estas categorias encontram-se, do mesmo modo, no campo dos valores vitais relacionada aos valores da sensibilidade vital, os quais são representados pela antítese nobre-vulgar, abrangendo todos aqueles valores da esfera do bem e do bem estar, e também os estados do sentimento vital, como a saúde e a doença ${ }^{(13)}$.

A prevenção de agravos à saúde é aspecto imprescindível no pré-natal, uma vez que qualquer 
infecção que acometa a gestante pode resultar em malefícios para ela, para o feto, e até mesmo ocasionar o parto prematuro. Em casos mais graves, pode ter como consequência o óbito materno e/ ou neonatal. Sabe-se que a maioria das mortes e complicações que surgem durante a gravidez, parto e puerpério são preveníveis, mas para isso é necessária a participação ativa do sistema de saúde ${ }^{(14)}$.

Então, as ações preventivas devem ser programadas, promovidas e definidas como intervenções orientadas para evitar o surgimento de doenças específicas, reduzindo sua incidência e prevalência nas populações ${ }^{(15)}$. Essa ideia da prevenção permite antecipar medidas para impedir que os possíveis males possam atingir as mulheres e seus bebês, por meio de exames específicos para detecção e tratamento precoce de doenças através das imunizações e hábitos de vida saudáveis que impeçam infecções.

A partir desses depoimentos, demonstrados na segunda categoria, foi possível dimensionar o grau de preocupação dos responsáveis pelo acompanhamento pré-natal com a prevenção de doenças e possíveis agravos, caso não haja ações de detecção e tratamento precoces.

O documento do Ministério da Saúde intitulado "Síntese de Evidências para Políticas de Saúde Mortalidade Perinatal", no que diz respeito à evitabilidade dos óbitos infantis no Brasil, destaca que os principais problemas que conduzem ao desfecho negativo da gestação são relacionados com falhas na capacidade de prevenção e resposta, em face de intercorrências durante a gestação, parto e puerpério, coincidindo com o período perinatal ${ }^{(16)}$.

Conforme foi mencionado, a prevenção de agravos é imprescindível, porém, nesse aspecto, há muito a ser avançado no dia a dia das consultas, com abordagens mais "simpáticas"(2) enfocando a educação em saúde; e também, há que se operacionalizar a oferta de exames, vacinas e a acessibilidade das gestantes a esses procedimentos.

Assim, é possível promover e favorecer uma situação em que a saúde seja vista não apenas como ausência de doença, e sim a partir de visão ampliada que tem a integralidade e a promoção da saúde como princípios norteadores da assistência ${ }^{(3)}$. Cabe, nesse sentido, o esforço de todos os profissionais para que o olhar de cada um esteja voltado para a pessoa alvo do cuidado, destarte ultrapassando os limites do puramente biológico.

Pontua-se como limitação da impossibilidade da observação da prática dos profissionais de saúde na consulta de pré-natal.

\section{CONCLUSÃO}

Em sua essência, o pré-natal visa o bem estar do binômio mãe-bebê durante toda a gestação, almejando desfecho adequado. E para isso, torna-se componente imprescindível, tanto pela consulta em si quanto pela preparação para os momentos subsequentes deste período. Compete ao profissional, portanto, apoiar e proteger a saúde das gestantes, baseando cientificamente suas orientações e condutas, objetivando sempre atender às expectativas dessas mulheres, respeitando suas escolhas e preferências.

Observou-se que os profissionais da saúde, médicos e enfermeiros, se apresentaram com o intuito de prestar a assistência pré-natal da melhor forma possível. Sem dúvida, tal esforço deve surgir de diversos âmbitos, em especial no que diz respeito às universidades, proporcionando formação voltada para os preceitos humanísticos; com relação à rede de serviço em saúde, esta deverá garantir a acessibilidade aos exames e seus resultados, recursos humanos e materiais.

Pretendeu-se com a divulgação dos resultados do estudo sensibilizar os profissionais de enfermagem quanto à necessidade de mudança nas ações de saúde vinculada ao acompanhamento pré-natal, com o intuito de promover uma relação mais voltada para a humanização, assim contribuindo para a qualificação do acompanhamento da gestante.

\section{REFERÊNCIAS}


1. Vieira SM, Bock LF, Zocche DA, Pessota CU. Percepção das puérperas sobre a assistência prestada pela equipe de saúde no pré-natal. Texto Contexto Enferm. [Internet] 2011;20(n.esp) [acesso em 02 out 2016]. Disponível:http:// dx.doi.org/10.1590/S0104-07072011000500032.

2. Scheler M. Esencia y formas de la simpatia. Salamanca: EdicionesSígueme; 2005.

3. Morais FRC, Coutinho e Silva CM, Ribeiro MCM, Pinto NRS, dos Santos I. Resgatando o Cuidado de Enfermagem como Prática de Manutenção da vida: concepções de Collière. Rev. enferm. UERJ. [Internet] 2011;19(2) [acesso em 12 out. 2016]. Disponível:http://www.facenf.uerj.br/v19n2/v19n2a22.pdf.

4. de Oliveira AS, Damasceno AKC, de Moraes JL, Moreira KAP, Teles LMR, Gomes LFS. Technology used by companions in labor and childbirth: a descriptive study. Online braz.j. nurs. [Internet] 2014;13(1) [acesso em 02 jun 2016]. Disponível:http://dx.doi.org/10.5935/1676-4285.20144254.

5. Barbosa TLA, Gomes LMX, Dias OV. O pré-natal realizado pelo enfermeiro: a satisfação das gestantes. Cogitare Enferm. [Internet] 2011;16(1)[acesso em 02 jun 2016]. Disponível: http://dx.doi.org/10.5380/ce.v16i1.21108.

6. Silva KL, de Sena RR, Seixas CT, Feuerwerker LCM, Merhy EE. Home care as change of the technical-assistance model. Rev. Saúde Pública. [Internet] 2010;44(1): [acesso em 12 out. 2016]. Disponível:http://dx.doi.org/10.1590/ S0034-89102010000100018.

7. Scheler M. Da reviravolta dos valores. 2ª ed. Petrópolis: Vozes; 2012.

8. Ministério da Saúde (BR). Conselho Nacional de Saúde. Diretrizes e normas regulamentadoras de pesquisa envolvendo seres humanos. Resolução n. 466, de 12 de dezembro de 2012. Brasília; 2012.

9. Weber M. Metodologia das ciências sociais. 5a ed. São Paulo: Cortez; 2016.

10. Guerreiro EM, Rodrigues DP, da Silveira MAM, de Lucena NBF. O cuidado pré-natal na atenção básica de saúde sob o olhar de gestantes e enfermeiros. Reme, Rev. Min. Enferm. [Internet] 2012;16(3) [acesso em 12 out. 2016].Disponível:http://www.dx.doi.org/S1415-27622012000300002.

11. Ferreira ABH. Dicionário Aurélio de língua portuguesa. 5a ed. Curitiba: Positivo; 2010.

12. de Lima TJV, Arcieri RM, Garbin CAS, Moimaz SAS. Humanização na Atenção à Saúde do Idoso. Saúde Soc. [Internet] 2010;19(4) [acesso em 12 out. 2016]. Disponível: http://dx.doi.org/10.1590/S0104-12902010000400013.

13. de la Cadena NB. Scheler, os valores, o sentimento e a simpatia. Revista Ética e Filosofia Política. [Internet] 2013;16(2) [acesso em 12 out. 2016]. Disponível:http://www.ufjf.br/eticaefilosofia/files/2009/08/16_2_cadena.pdf.

14. Ministério da Saúde (BR). Secretaria de Vigilância à Saúde. Secretaria de Atenção à Saúde. Política Nacional de Promoção da Saúde - Revisão da Portaria MS/GM nº 687, de 30 de março de 2006. Brasília: Ministério da Saúde; 2014.

15. Czeresnia D, de Freitas CM. Promoção da saúde: conceitos, reflexões, tendências. 4a reimpressão. Rio de Janeiro: Editora Fiocruz; 2016.

16. Ministério da Saúde (BR). Secretaria de Ciência, Tecnologia e Insumos Estratégicos. Departamento de Ciência e Tecnologia. Síntese de evidências para políticas de saúde: mortalidade perinatal. Brasília: Ministério da Saúde; 2012. 